\title{
Language of Violence in Social Media: A Linguistic Cognitive Study
}

\author{
Jinan Al-Tamimi \\ Prince Sattam bin Abdulaziz University, Saudi Arabia
}

\begin{abstract}
Language is not a fixed structure, but a changeable group whose contents the violence. First, we do not choose our native language. Second, we do not choose the concepts prevailing in our culture. However, we have neither the capacity nor the choice to escape the power of language. This research presumes the existence of the phenomenon of language violence in dialogue with the other, in dialogue with oneself, as well as hidden violence in language. It also presumes that this phenomenon has cognitive dimensions through which violence structures are built into general concepts, which are feared to be physically realized in reality. What arises within the language may be processed within the language before it appears in reality. This study examines the cognitive dimensions of language violence and its recent manifestations of social networking by analyzing selected models of social media by taking advantage of cognitive linguistic data to figure out the cognitive images of language violence used by social media dialogists/interlocutors. In other words, it is an attempt to reveal how words and compositions are used as a weapon by which the speaker attacks the dialogist. This study does not abide by strict time limits but adheres to the study of the phenomenon in models of expressions currently used on social media. On the other hand, it discusses the roots of violence in models of expressions in the Arab heritage in the past. All these contexts are in peace, not war.
\end{abstract}

Index Terms — language, cognitive linguistic, violence, social media

\section{INTRODUCTION}

Just as the peaceful cooperation among human beings appears, so does violence in human societies; But when violence turns from an urgent matter of self-defense or property protection to a justified behavior in words or actions, here violence becomes a devastating threat that requires urgent treatment to save its victims. Addressing violence within language represents an implicit agreement to reject violence altogether, which means refusing to utter its words first, and refusing to agree to the circulation of violent concepts second.

The effect of language on thought and on the direction of culture is so prominent. Language makes culture on the one hand, and culture on the other, makes language. But the problem here is that a human evolves very rapidly and many of his concepts change, which may actually fade out of existence, but they remain stuck within the language that he uses. The danger of language here lies in reproducing texts with violent contents and repeating them in modern contexts that promote their acceptance.

When I wrote this paper, it became clear to me the extent of the damage that violent language inflicts on the soul and body. The frequency of encountering those violent words that I collected during this study, even though these words were not directed at me personally, caused me psychological distress and extreme discomfort. Here, I would like to underline the importance of studying this subject linguistically, psychologically, socially and technically as well; to provide appropriate solutions to address this issue, to purify the human language in general and Arabic in particular from any violence that distorts the face of human civilization.

Among the most important findings of some previous studies on language violence is that the use of colloquial language in the realization of violence makes it more dangerous and more effective. "Language violence tends to be more intense when political discourse makes use of the vernacular and is met with a counter-violence more harsh than it. This violence permeates the society, so reflected in the behavior of its members, and becomes an inherent characteristic of it". Language violence also appears in conversations, which is manifested "in adjectives of slander in the colloquial dialect and their expressive ability to create words that specific to the linguistic community and derived from dialect environment, its senses, its terrain, and its conception of the universe and life". Saad al-Dukkan (2016) indicates that the power of language makes it an important responsibility on the shoulders of linguists: "When its speakers, who belong to it, in its various fields and fraternal branches, call for the necessity of exposing the fallacies of violent discourse."

This research assumes that social networks is an open digital space which gives complete freedom of expression in the same language that people speak in their daily conversations, and that such an unfettered freedom indicates many dangers in using language as a tool to inflict harm on the other, thus creating violent reaction to counter these linguistic attacks. From social networks, we chose "Twitter" as an analytical evidence model that employs language to realize violent purposes.

Before beginning to present the themes of this paper, it is important to differentiate between two important terms: "Violence of Language" and "Language of Violence". What is meant by the first term is the violence that a language, by 
its nature, imposes on its speakers through an authority that exists in the language itself and another symbolic authority that the language acquires from the social status of the speaker. Language with its authority may force us to do with our words or our thinking what we do not like to do that when it restricts us to limited choices of words. As for what is meant by the second term "Language of Violence", it is the use of language for realizing violent purposes and charging the words with desires of inflicting psychological or physical harm on the other, or on oneself.

\section{THE CONCEPT OF VIOLENCE}

In Arabic dictionaries, Al-'Ounf (violence) is defined as being against Al-Rifq (kindness). I reprimanded him: i.e. I scolded him, blamed him and reprimanded him with the words. And Al-'Aanyif (violent words) means: harsh words, and from that is what Abu Sakhr Al-Hudhali said in addressing his satire to Ta'abbata Sharran: (innuendo التعريض)

Fa-'Ina ibn Turna 'Idha Ji'atukum *** Araho Yudaafi'au Qawlan 'Anifan

In English literally translates as:

If I come to your land, Even Ibn Turna $* * *$ I think he will be insulted with violent words

[Ibn Turna is a metaphor for the mean person]

Violence is defined idiomatically as: A set of behaviors aimed at harming oneself or the other, and it comes in multiple forms, such as hitting, quarreling, destroying or damaging, and verbal violence such as threatening, instigating sedition, innuendo, stinging joke, and everything that leads directly or indirectly to inflicting harm.

According to the previous definitions, violence is an act against and harms the other, which, in its cognitive dimension, is a sensory thing that occurs from and falls in language. In the struggle over power, human beings choose verbal rather than physical violence, so they replace their physical weapons with symbolic tools (the words) because these tools keep them away from getting hurt or killed. In order to liberate the concept of violence in language, we define the metaphors by which violence is practiced against the other and sometimes against the self. The violence inherent in any society uses words as a weapon of conflict, and makes language a field of war, as language, as described by Jean Lecercle, is the field within which current conflicts being played out. In other words, it is language that conveys to us the hateful racist views, and at the same time is the area where racists are moving. Linguistic violence is inflicted by words, and it also occurs within words. The danger of coercion of language lies in language's acknowledgment of the already existing words of violence or racism.

Violence is a disease or epidemic that feeds on and thrives in language and is finally realized outside it in physical reality. The danger of the symbolic power of language comes from its ability to create violence through verbal expressions. This power of the language, its effectiveness is not realized only if it is recognized by accepting it when being silent about it or by acknowledging it through its circulation, and here, the dominance of language emerges. Ethnic genocide, for example, is not a spontaneous event or the result of a sudden moment, but the result of a history of texts circulation by agreement and support, texts charged with revenge and nostalgia for the past, which feeds violent language and contributes to the realization of violence on the ground.

\section{The LANGUAge CONCEPT}

De Saussure defines language as a system of signs for expressing ideas. Language, even if it appears to us as a tangible thing, in sounds or written forms, however, it represents a set of events. Words are instruments of thought. Just as ideas have an individual aspect represented in their expression, they also have a social aspect represented in receiving and accepting them. Because language is a social phenomenon, it cannot emerge without the existence of a society; and words do not acquire their significance or meanings except within this social order. Accordingly, "the study of language, in terms of the social conditions in which it functions and develops, falls within the field of the scientific study of societies."

Sapir believes that language is "a purely human, not instinctive, aimed at communicating ideas, feelings and desires by means of a system of symbols chosen by a society." Searle argues that the speech act is the smallest unit of human communication, by which the speaker exercises an action towards the recipient and wants to bring about what he means by his saying. This is clearly reflected in the meaning of a simple speech when the speaker intends what his words exactly mean, and here the speaker has the intention to produce an effect or an action that is directly mentioned in the speech; in another words, the speaker seeks to have the recipient know his intention in a direct way. But the meaning of a speech is not always simple and straightforward; as there may be hidden hints are implicit in the saying such as irony, sarcasm, or metaphor.

In his book "Language Violence", Lecercle differentiates between the system of language and the remainder of the language, even if he finds them intertwined and living together in linguistic activities. While the language system follows the grammars and the prevailing norms in society, the reminder of the language breaking out of the prevailing linguistic paradigms and cannot be described or subjected to a specific system. The reminder exploits and violates language rules. In Lecercle's view, metaphor has the greatest influence on the remainder of language. In the view of Lakoff and Johnson, language is a source of inference about the cultural metaphorical structure that shapes the nature of our thinking. Metaphor is not a purely linguistic figure, but rather a cultural phenomenon, by which language is affected, 
and can be well explained by assuming conceptual correlations between one field of perception and another field of expression.

Language plays an important role in physical reality; it is not a description of already existing events but rather a description of the partial creation of them, and the symbolic aspect of language is an essential part of the construction of actual reality. According to Austin, speech acts can be broken down into two types of intentionality: The first type is the directive acts, which are intentional in essence such as direct commands or prohibitions, or verdictives. The commands push you to do the act and prohibitions push you to avoid the acts, and the verdictives convince you to accept or reject. Here, "the effect of that directive act appears on the listener, such as urging, persuading, or expecting someone to do something." The second type is perlocutionary acts that may or may not be intentional. This speech act is not directly intended but leads to consequences for our actions.

Language connection to reality is through circulating the meanings of its words, and it is the meaning of words that transforms speech into actions that appear in reality. In order to address the reality of violence in the language, it must be withdrawn that the collective acceptance of circulating or justifying notions of violence within language and declaring them in the faces of others or towards oneself. The most powerful influencer that leads to the disappearance of this violence is the refusal to practice and convey it in word and deed. We not only use language to perform the functions of communication, but by the words of the language we also perform actions; by language we do harm, and by language we make good, and by language judgments are issued, and a person dies or lives. Our words are part of our actions, and with every word we utter or write, an action generates and makes an impact on the ground.

\section{NETWORK COMMUNICATION CONCEPT}

Networking communication is the communication that takes place between digital individuals on social media. Social media can be defined as: digital communication tools based on the Internet, and allow people to interact with posts, pages of friends or followers. Among the most famous social media are: Facebook, YouTube, Twitter, Pinterest, Snapchat, and other social networks that have recently increased rapidly.

Registration on social sites required choosing a pseudonym that will be your identity on these sites and a password, which will serve as a user identification card, and a candidate for membership in a social network must agree to the terms of an agreement that sets out his/her "digital" rights and obligations. A social media user may be subject to penalties such as deleting his/her account or freezing it as a result of unethical or immoral practices that a digital citizen may do, as social media sites represent a virtual country in which individuals enjoy freedom and protection by the administration of these sites.

When personal identification is up to the user, participating individuals can use pseudonyms to represent their identities. Research on this type of social interaction, in which real identity is hidden or not known, has indicated that it allows individuals to explore their repressed identities and get to know themselves more in a somewhat safe manner. Because of the opportunity of having an alternative anonymous identity and that your actions have no consequences for you and will not be linked to your real identity but to the virtual identity you have chosen on the virtual space, perpetrating aggression against and bullying of others becomes easy.

The speech act on social media is not explained by its meaning but by its effect. The language of conflict or antagonistic scenes on social media is part of the actual world, where the relationship between words and the intentions of the interlocutors/speakers is not one of representation but one of interaction; if a tweeter or commentator writes a word, it travels from the commentator's screen to the recipient's screen. This word constitutes a meaning that can have physical effect on the body of a recipient who receive these meanings in the form of words but they do harm in his body as bullets do or what a weapon does. The materiality of linguistic practices makes language violence dangerous and directly affecting; the violence inherent in the insult is not due to the high-pitched voice, but to its incorporation into a well-established practice in a series of affecting expressions.

\section{The Roots of Violence in the Arabic Language}

The concepts that control our thinking, according to Lykov and Johnson, show what we are aware of and how we deal with the world and with people, so that the conceptual format plays a central role in determining our daily realities, and that our conceptual system in a large part of it is metaphorical in nature.

Before we begin to analyze any model of linguistic violence, dear reader, we must initially agree to recognize the existence of what is already called linguistic violence. The existence of the term "linguistic violence" is an implicit agreement that, this linguistic or social disease exists. This is the beginning of diagnosing the disease and determining its roots and locations. The fact that a language does not contain a specific term does not indicate that the culture of such a language does not contain the concept of this term. This is in contrast to Russell's conclusion, who believes that the absence of the term "ineptus" (impertinent) from the Greek language indicates that the morals of the Greeks are so high that they did not need a word to describe this disease. On the contrary, Cicero concluded that this disease was very common to the degree that they were not even aware of its existence. The recognition of the existence of the concept of linguistic violence in the Arabic language, hence, is the beginning of a correct diagnosis of it. Our access to the concept of violence in language means that the culture consciously reaches out to the diagnosis of the disease to begin to cure it. 
By envisioning violence as a disease that can be combated, violence becomes a biological condition that can be treated, thus strengthening the language's immune system to resist any emerging viruses of violence. By relying on linguistic data, we can determine the perception of violence in the Arab mindset by searching for its roots in traditional texts first, to give an idea of what makes feelings or controversy are depicted as violent scenes of war and physical conflict, or makes language words are depicted as weapons by which humans kill each other. It is important noting that, this depiction is not just a linguistic metaphor but what is depicted in it is absolutely achieved in feelings or situations. When we talk about the controversy as a war, one of the two sides of the controversy may "actually" win or lose; a person he argued with him is considered an adversary; the words he says are for defense or attack; and one of them may besiege the other by "words". And "in this sense, borrowing a controversy as a war is one of our cultural metaphors that we live by and that show the activities we perform when we are arguing." In the past, the Arabs were aware of what words can do, so they said: "Al-Harb Awlha Kalam wa Akhirha Essttilam" (literally meaning: war begins with words and ends with bloody battles). The Arabs pointed out the great influence of language on souls and bodies, and that the injuries caused by words to the body are more painful and harmful than that caused by arrows and swords, some of them said: "Jarh Al-Kalam Ashadu mn Jarh Al-Siham" (literally meaning: the wounds of words are worse than the wounds of arrows). Al-Jahiz in his book "Mahasin wa Azdad" under the title "Mahasin Hifz Al-Lisan" (literally meaning: the advantages of keeping silent) quotes the words of Aktham bin Saifi: "Maqtal Al-Rajol biyn Fakkaiyh" (literally meaning: The killer of a man is between his jaws [indicating to the human tongue]). A poet said:

(V1) Wa Jurho Alsayf Ta'asawh Fibra***Wa Jurho al-Dahr ma Jarh al-Lisano

(V2) Jirahat at-Ti'aan laha Ilti'aamo***Wla Yaltam ma Jarah al-Lisano

In English literally translates as:

(V1) A wound of the sword, if treated, will be healed

*** A wound by the tongue (speech) would not heal

(V2) Stab-wounds will heal $* * *$ But a wound caused by the tongue will not be healed

Here, in these poetic verses the knowledge of words is built by depicting them with concepts and relations (metaphors) derived from the domain of war: that is, building the concept of [the word] by depicting it with the concept of [the weapon]: i.e. depicting the word as a sharp tool that causes wound or stab. The first domain has been called the "target", and the second is called the "source". For Lakoff and Johnson, metaphor is based not so much on similarities as on mapping. The relations are based on a penetrating process between two domains, one is a target domain and the other is a source domain, as there are correspondences between the two domains.

Nasr ibn Sayyar said:

Fa'iina al-Naar bil-Awdain Tuthka***Wa 'ina al-Harb Mabda'wuha al-Kalam

In English literally translates as:

A fire is generated by two sticks***A war begins with words

In these poetic verses, language is portrayed as a tangible entity, and words are portrayed as tools used to realize certain functions or goals; The poet deals with the tools of language as weapons that inflict harm on the victim's body. So the word is a sword, the injuries of words are not expected to be healed, and the word is maybe a small spark that ignites a great war. Although the Arabs have noticed the manifestations of linguistic violence and referred to it in more than one place, the Arabic grammar books contain many linguistic exercises that show violence; it appears specifically in Arabic language verbs that describe the actions practiced by one individual on another, the most prominent of which is the act of beating that always falls on (Amr, boy and servant), for example: "(Ay Rajol Dharabt) meaning (Which man did you hit?); (Zayd Dharab Amr) meaning (Zayd hit Amr); (Hal Tadhriban) meaning (Do you (dual) hit?); (wa Dharbi al-Abdo Mosaian) meaning (Beating a slave by me is a bad); (Dharab Gholamha Gar Hind) meaning (her boy hit Hind's neighbor); and (Al-Dahribat Gholam Al-Rajol) meaning (the female beaters of a man's boy).

The violence of language does not appear in the expression of harm to others only; Violence may be used in language to express feelings of love and longing. Al-Sarraj, in his book "Massari'a Al-Ushshaq," conveys to us this poetry verse of Ahmed bin Obaid:

\section{Ra'ayt Suyuf Albayin eind Firaqiha***Bi-Aydi Junuwd al-Shawq, bil-Mawt Tadfa'u}

In English literally translates as:

When she is gone I saw the swords of farewell

***in the hands of the longing's soldiers, that galloping and coming with death

In the previous poetic verse, we see the words of violence are used to describe the scene of announcing the farewell, as longing is an army that wields deadly swords in the face of the lover and drives him to death. This book of Al-Sarraj is replete with the use of violent expressions to describe love; for example: the eyes kill, love kills, the lover is a martyr, and the lover is killer.

The roots of violence in Arabic "which are represented in those expressions used to describe love or those of grammatical exercises, in addition to the expressions that directly call for killing as a matter of courage and daring" reveal violent concepts implicitly agreed upon by evidence of their abundance in literature and grammar books.

\section{Cognitive Dimensions of Linguistic Violence}

\section{A. Violence agonist the Other}


There are two types of linguistic violence in social networks. The first type is in the context of actual war and the words of violence that bloggers (users) mention on social media and intend their literal connotation, which are phrases derived from the domain of combat, such as: (Al-Thar [revenging], Al-Qatl [killing], Al-Tamthil bil-Jasad [mutilation of body], Al-Tadmir [destruction], Al-Qasf [shelling], Al-Tafjir [bombing], Al-Nail Minkom [attacking or killing you], Al-Ibadah [extermination]...etc). Such linguistic violence is justified in the context of a war that actually inflicts violence on physical reality. The second type is patterns of linguistic violence that exchanged by dialogists/interlocutors in times of peace and in the context of talk about the religious, cultural or political issues of daily life, and in which, the same expressions from the same domain (fighting) are used.

The simplest linguistic discussion between two parties (two people) is described as a conflict or war in which one party is victorious and the other is a loser. Social networks represent a vast field for these language wars, as discussions are war, dialogue methods are tools of siege, retreating from confrontation in a dialogue war is cowardice, and when the addressee person wants to incline towards peace, he may raise terror in the heart of interlocutor/speaker who wanted to fight using language and have advanced war tools such as the original method that enables him to besiege others. All this is reflected in the following tweet:

"Most of the intellectual disputes today have become like this (Do not discuss me, do not debate me, do not besiege me), and follow the original method in the science of controversy and disagreement like (Just search in Google for information and evidence as I do; let me say what I want; do not oppose me; that is not your concern; and I am free in what I think). Terrifying superficiality. ” See the tweet in (Fig. 1).

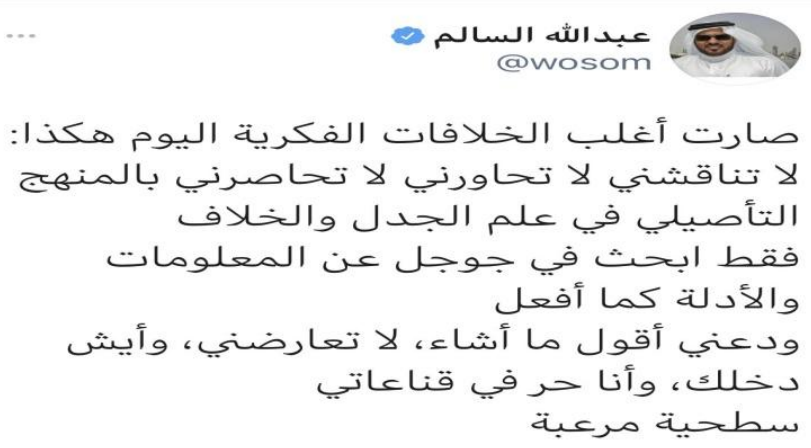

Fig. 1

Linguistic violence sometimes appears as a call to inflict physical harm on the other, in which the speaker specifies the parts of the body that he wants to stab with knives of his/her words and directs them directly to an addressee person in many forms, for example: praying/supplicating against him, insulting him, cursing him, or threatening to inflict physical or psychological harm on him. Perhaps one of the most prominent forms of linguistic violence in terms of their circulation among people is that appears in the form of "praying/supplication", in which the speaker person charges his words with the strongest meaning in existence when he asks Allah (the Almighty) to fulfill his violent desires, and then directs the arrows of his words towards the addressee person, saying for example: "May Allah cut off your tongue and paralyze your body pillars." See the tweet in (Fig. 2). The speaker (the author of this tweet) here will appear innocent of the direct act of violence on the victim's body, since the actor of violence here will not be the speaker himself, but according to the wishes of the one who prayed/supplicated (the speaker or tweeter), violence will fall on the victim by Allah's command. The speaker justifies such a violent statement to himself because he sees himself outside the framework of the accusation of violence and his hateful and violent desires are attributed not to himself but to Allah; thus, he makes himself immune from being charged with a violent crime.

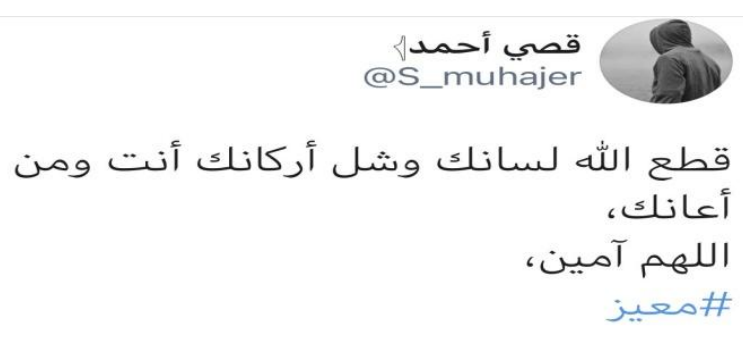

Fig. 2

This supplication which calls for direct violence towards the person against whom the supplication was directed and towards every person who assists him, was not a violent reaction to violence directed against the supplicant, but rather a response to a tweet by another person expressing his opinion on a religious issue. See the tweet and reply in (Fig. 3). 


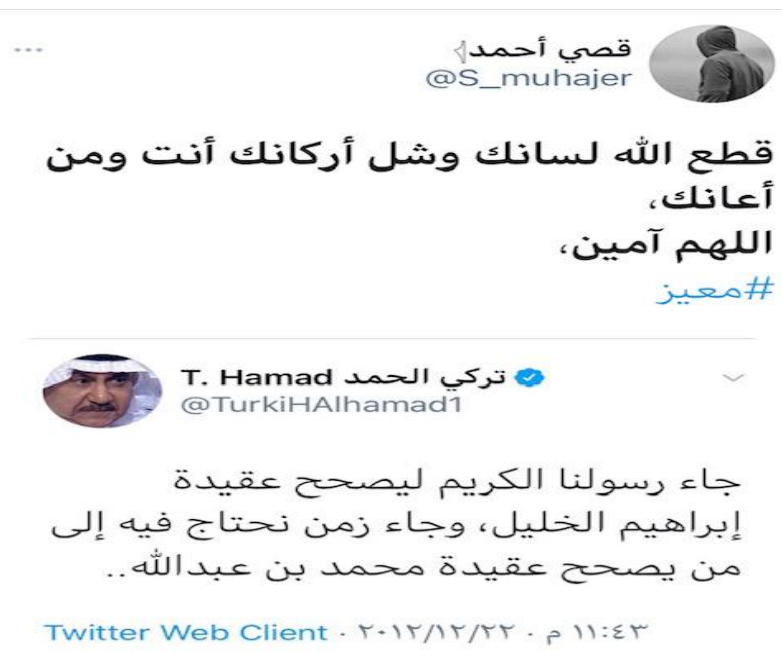

Fig. 3

Among the linguistic violence that which incites the infliction of physical harm to a specific person and alludes to what some terrorist groups are notorious for that cut off human heads, one of the tweeters specifies the part of the body that he wants to inflict violence on, tweeting: "Feel your neck... we will avenge", with a direct threat indicating the writer's desire to cut the neck of the addressee person or his desire to realize this matter at the hands of others. See: the tweet in (Fig. 4).

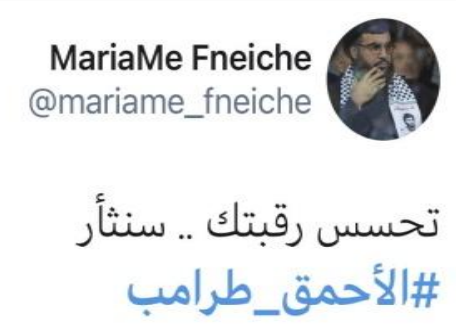

Fig. 4

In the context of someone's victory in a dialogue, the language turns into missiles that bombard and explosives that blow up the forehead of the addressee person, by a tweet saying: "By Allah, he blew his forehead," meaning that he (a third party) embarrassed the addressee person and proved the corruption of his argument with the power of proof and defeated him. This linguistic violence is accompanied by laughter and rejoicing with the thrill of victory. See the tweets in (Fig. 5, Fig. 6).

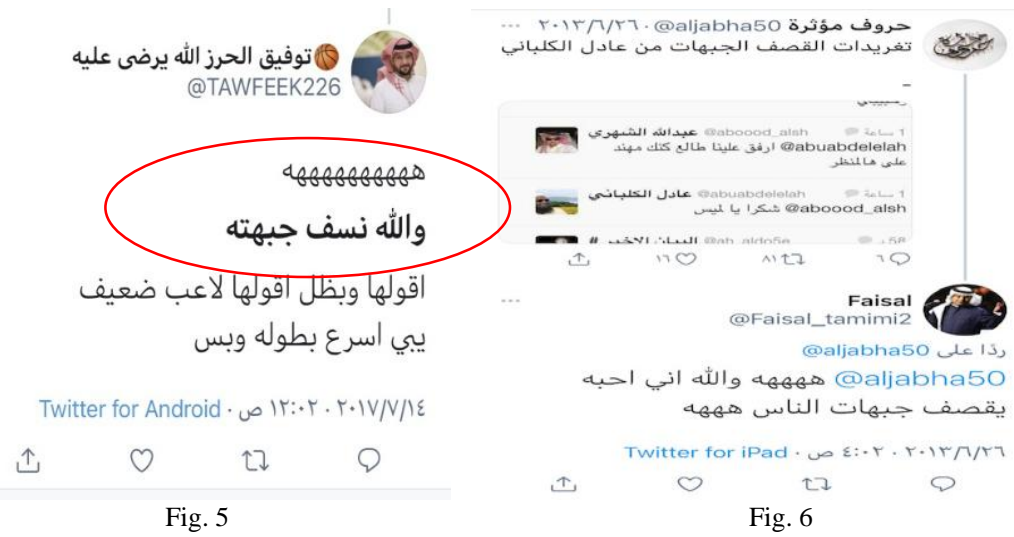

Direct hate speech is verbal aggression when the speaker person exploits language resources to express racism against some groups with the aim of causing psychological or physical harm to the addressee person, while incitement speech is the incitement of followers or addressees to ostracize a group of people or an individual. "Hate speech" can be defined as: "racist expressions against individuals or groups of people that based on gender, race, skin color, citizenship, political opinion, sexual orientation, or geographic range." 
Violence also seen in taking religious texts out of their context and using them in a context that contributes to people's feelings of hate and desire for revenge, in order to incite against a certain group of people by using texts that depict scenes of torture of criminals in the afterlife to surround the addressed person by a frame within this violent scene, and the speaker person here grants himself "the authority of Allah the almighty" and gives himself the right to specify whoever he wants and according to his opinion those for whom these verses were intended. See the tweet in (Fig. 7).

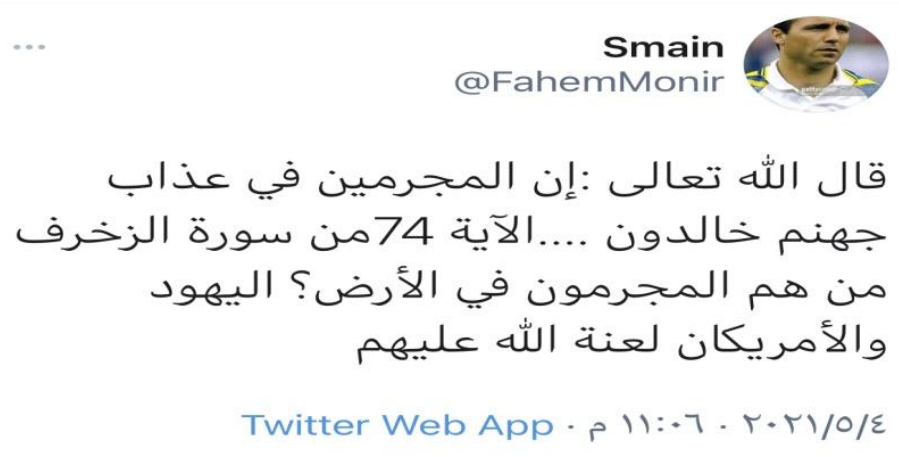

Fig. 7

A translation of the tweet in Fig. 7 is as follows: "Allah the almighty said: 'Indeed, the criminals will be in the punishment of Hell, abiding eternally.' \{Surat Al-Zukhruf (43), verse (74)\} .... Who are the criminals in the land? The Jews and the Americans, May Allah curse them."

The speed of intuition and mastery of language gives a person a power to confront his opponents; Language is a tool of strength, and the dominance in social situations is always for those who are skilled in language. One of the strategies that some dialogists/interlocutors or sometimes intruders use is that of asking direct personal questions to the addressee. This is because the question is a weapon that surprises the addressee (who they're speaking to) with the aim of stripping him of his weapons, making him on a defensive instead of an offensive position, or the goal of questions of curious people may be to bring the addressee out of a state of peace into a state of war with them. A direct question by an unknown person, or by a known person who possesses any kind of authority, through a text message without greeting, identifying the questioner's identity or mentioning the reasons for his/her question, may be a weapon that penetrates the privacy of the person to whom the question is addressed. Even if the message is something like: "How's it going?" Intrusive questions in our cognitive perception are a direct invasion of privacy, because every direct question is a compulsive intrusion; the questioner or the inquirer may know what is there and what he will find, but he wants to find the answer himself and bring it to light. Here, the goal of language is not to inform or communicate, but rather, it is to extract the answer, and to establish an authoritarian relationship between the questioner and the person to whom the question is addressed, by the question itself. The same is true whether the question is a repetitive or urgent personal question, or a formal question in a formal interrogation. Both represent authority over the person to whom the question is addressed (the person questioned).

When one asks the other in an intellectual discussion: "What is your religion?" or "Are you a Muslim?"; he definitely wants to get out of the discussion and invade the other's privacy like a thief breaks into your home and steals your possessions to use them as a weapon against you. Let us consider the dialogue in (Fig. 8): The first dialogist raises a question as a weapon in the face of the second dialogist in order to invade his privacy and explore his identity, by tweeting: "....... the ${ }^{*}$ question is: Are you a Muslim or not?" The second dialogist gives the first what he wanted, by replying: "I am a Muslim, praise be to Allah." And here after the second dialogist snatched what he wanted from the first dialogist, he used that as a weapon and directed it against the first dialogist, by asking him another question, taking him outside the Muslim community: "Ok, you say that you are a Muslim. But why do you disbelieve in the Holy Quran?" 


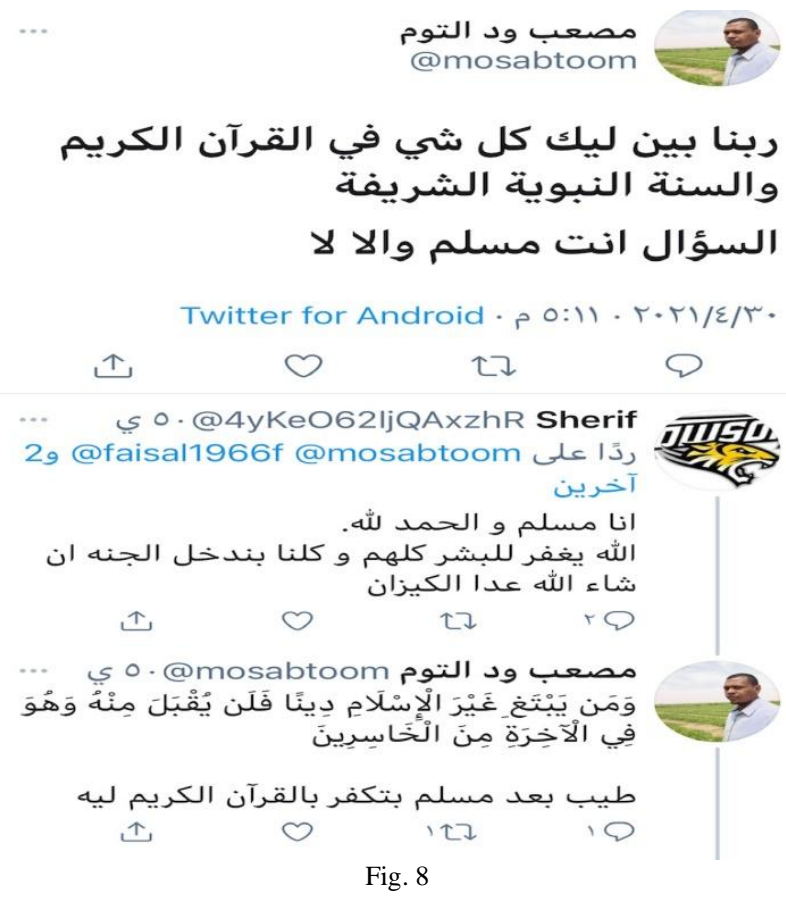

Linguistic violence is not only in the words that call for a shift to physical violence, but in building cognitive perceptions of groups or individuals when it is established for them within their mother tongue that they are outside the framework of the peaceful human community. Hence the dangers of linguistic violence that justifies the isolation of some individuals or groups within barriers that are denying them the right to a safe life, or that makes it easy for others to attack or kill them.

What about other people who are unable to participate in a dialogue and are content with silence or remain silent? They do not express their reaction. They suppress feelings of anger or desire to harm. Silent people influenced by the language are perhaps more lethal than those who spoke the "language of violence"; Because there are instigators of violence by the language and there are actual perpetrators, and violence by reproducing historical texts is the most dangerous type of violence. The soft method may be the most successful way to practice symbolic violence, in cases where the prevailing balance of power does not allow recourse to open violence (Bourdieu, 1994).

\section{B. Violence towards Oneself}

It was expected at the beginning of writing this research that the language of violence against the other is dominant in the dialogue between people, but when observing the expressions of violence in the Arabic language, I found that the violence directed by a person towards himself is more than the expressions of violence with which he/she faces his/her opponents!. This is often in the context of a joke to express regret for an action.

A human uses language to inflict violence or harm on the other, and on the other hand he/she uses language to resolve conflict and address problems between him/her and the other. In language violence originates, and in language violence dies. However, it is strange for a person to practice violence towards himself/herself with words, he/she may insult or curse himself/herself, or make the words of the language knives with which to stab his/her body or distort his/her soul; One of the tweeters says: "I am inhabited by a soul that I no longer control, driving me strongly towards a doom that my mind has distinguished well. This spirit no longer cares about my body or even my mind, which has long held it. It flees from me and only comes back loaded with fire that ignited my heart until I became a block of fire." See the tweet in (Fig. 9). We note in the previous tweet that language is a source of pain, although not directly, but through the violence that language literally inflicts on the writer's body and mind. It is violence from the self towards the self, which he/she inflicts on himself/herself with the weapon of language. He/she charges the words with feelings of anger and hatred and draws from them imaginary characters who drag him/her towards a doom and with the language, ignites fires that burn him/her and turn his/her heart into a mass of flames. 


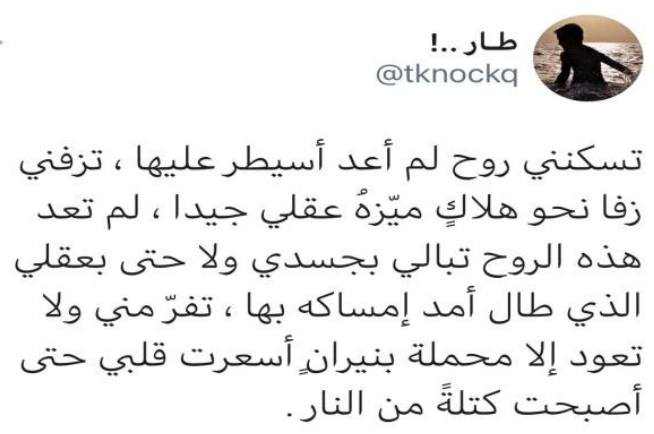

Fig. 9

Often a person practices violence towards oneself after a person does something that he/she thinks is wrong, as if he/she is punishing himself/herself with language to relieve himself/herself of guilt. For example, a female-tweeter says in this respect "I wish Allah had cut my tongue before I promised her to go out with her tomorrow, " and another says "I feel like I would stab my heart." See the two tweets in (Fig. 10). In the two previous models of tweets, we saw how a person directs towards oneself the most extreme types of physical violence (cutting the tongue) and (stabbing the heart).

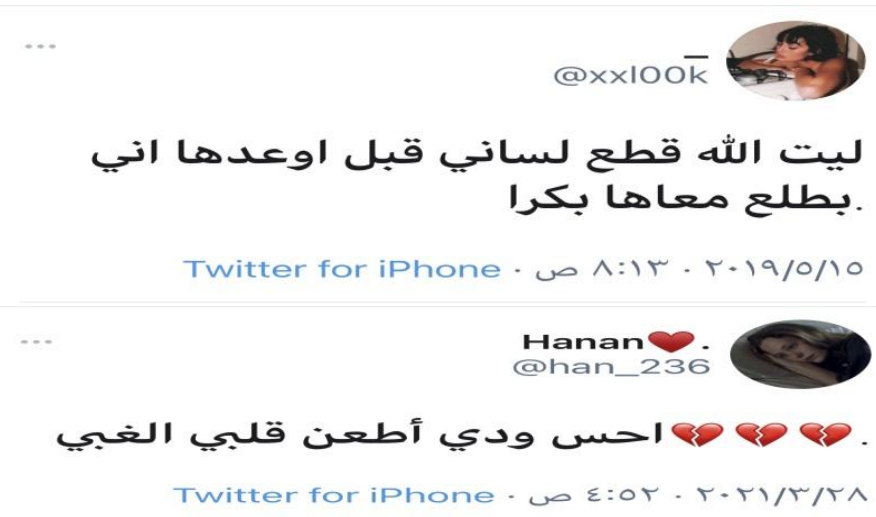

(Fig. 10)

A person may pray against himself with death and destruction, for example, a tweeter says, "May Allah takes me," and here we note that the execution of the act of violence declared by the speaker against oneself is executed by Allah's command. Or a person declares his/her desire to punish oneself with flogging, as one of the tweeters in this respect says, "I would like to flog myself, I feel that I deserve to be flogged for my stupidity, my Lord, I wanted to flog me for a long time. I am conquering myself," It is noted here that the act of violence (flogging) is performed by a person against oneself and is repeated three times. Another tweeter in a tweet asks Allah to break his hand! He said "Why do Twitter messages not be deleted or disappear? May Allah make my hands break." See the two tweets in (Fig. 11). 


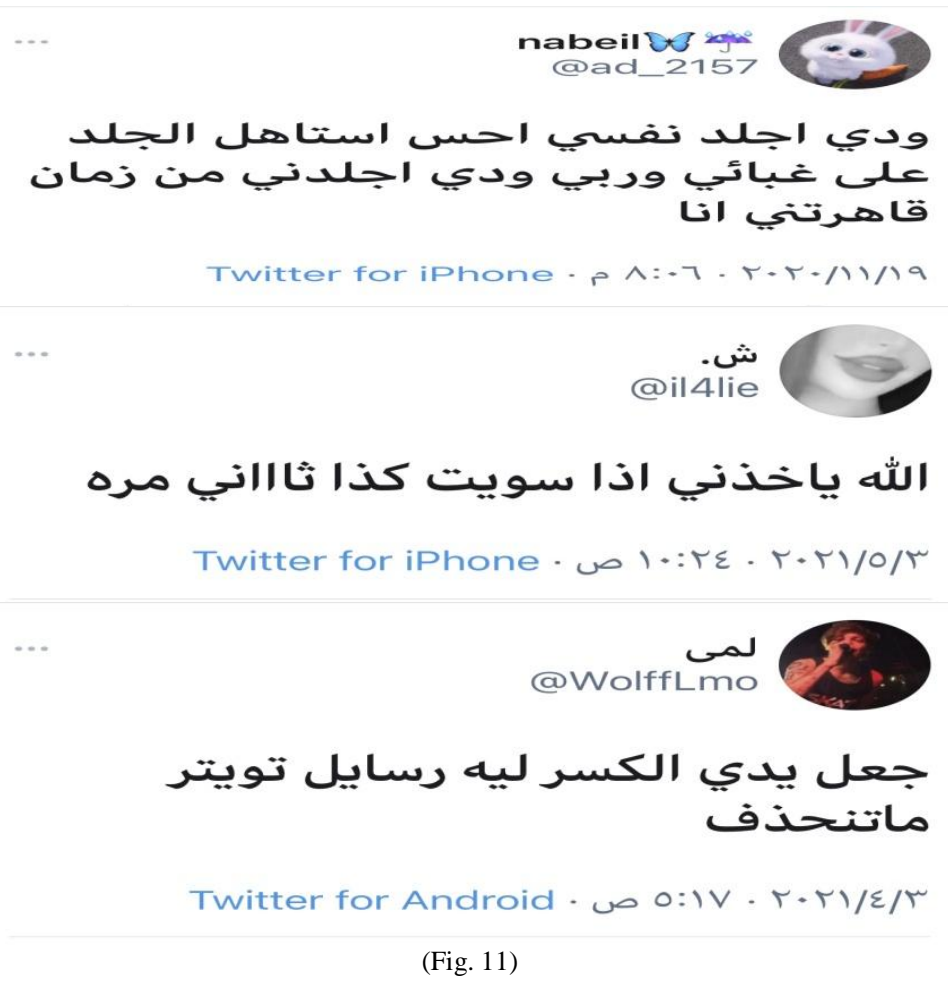

Here we ask: Does a person really mean to harm oneself? or that he/she only expresses his/her feelings of guilt and punishes himself/herself by using the language, but he/she does not really mean that this violence be carried out against him/her outside of language. Studies on the phenomenon of self-injury (more commonly known as self-harm) conducted in 2008 in England provides us with the answer to that question: the rate of individuals who self-harm $33 \%$ and $32 \%$ of them had intentionally cut or burned themselves.

So the violence that appears in language/speech may be an actual reflection of an inner desire to self-harm. Psychological studies have dealt with this phenomenon seriously to investigate its causes and manifestations. What increases its danger is the ease and speed of its spread over the Internet, by means of words and sometimes pictures. Facebook and Instagram have pledged to delete any pictures that show scenes of self-harm. Will we witness a ban on any language expression that calls for violence towards oneself as well?

Language alone does not have the power to prevent violence. But the spoken word bears the seed from which physical aggression sprouts. Because the seed of physical violence is first planted in the land of language. Violence diseases can only be treated with the drug of peaceful language, agreement and convention to replace the violence of words with the expressions of kindness. It should be noted that studying this subject made me, on the one hand, aware of the danger of violence that the inner language exerts on the soul, or, in a more precise expression, the seriousness of the violent words that we direct towards ourselves, and on the other hand, aware of the extent of the great psychological harm that some groups of society are constantly exposed to; Because of the violent language they see every day on the rapid growth social networks.

As long as we can control reality in part by language, through enacting legislation, laws, and regulations, and as long as we can by using language accomplish the peaceful actions that dominate the violence they contains, so Why don't we describe the dialogue as a duet dance, for example? or describe love as a state of peace and tranquility, and words become tools of strengthen construction, not incisive weapons and shovels of destruction. Can we change the language so to change the culture, or does the change must begin with culture and end with the language? The symbolic power of language may be able to form a new view of the world, or transform the worldview, but it will not be effective unless the linguistic community recognizes its legitimacy. What gives words their power is the belief in their legitimacy, and the authority of those who speak them and produce new words, or reproduce old words in new contexts.

\section{CONCLUSION}

The roots of violence in the Arabic language lie in the grammatical and literary heritage, and the danger of violence in the heritage lies in its sanctification without considerations of the context in which violence appeared and in its reproduction in a modern context as a weapon with which to confront opponents. The violent metaphors that appear in the Arabic language are a direct reflection of the system of cultural perceptions in Arab mindset. The cognitive dimensions of linguistic violence can be generally classified into the following three dimensions:

1- Language is a material entity made up of weapons (the words). 
2- Language is a field of conflict, violence and self-defense, and a place where a person punishes himself to relieve his feelings of guilt.

3- The cognitive content of the language is an army that uses its tools to besiege opponents.

\section{Recommendations}

At the end of this research, we recommend proposals for future studies aimed to address the seed of violence in language before it grows and bears its toxic fruit on the ground, by criminalizing linguistic violence of all kinds, the most dangerous of which is implicit violence that uses language in constructing mental images that terrify and frighten people; and aimed to replace violent words with peaceful ones. On the other hand, changing by creating nice metaphors to describe words, love, dialogue or argument contributes to treating the phenomenon of violence within language, and thus builds a nice perception about language and what happens within language or things which language describes.

\section{The suggested studies include:}

1- The impact of linguistic violence on adolescents who use social networks.

2- Cognitive dimensions of linguistic kindness in text messages.

3- Linguistic violence in education community.

\section{REFERENCES}

[1] Al-Dakan, Mohammed bin Saad. (2016). Thresholds of violence: How does terrorism arise through language? Arab Journal of Sciences, Imam Mohammed bin Saud Islamic University, 41, 195-265.

[2] Al-Helweh, Nawal bint Ibrahim bin Mohammed; \& Al-Qasim, Judd. (2016). The Violence of Language (in Arabic). Jusoor Journal: Mohammed Al-Abd, 4, 143-172.

[3] Al-Jahiz, Amr ibn Bahr. (2002). Advantages and opposites (in Arabic). Dar Al-Hilal Bookstore, Beirut.

[4] Al-Sarraj, Jaafar bin Ahmed bin Al-Hussein. (Died: 500 AH). Masari' Al-Ushshag [Fates of Lovers] (in Arabic). Dar Sader, Beirut, (n.d.), p. 160.

[5] Al-Saran, Mahmoud. (2013). Linguistics: An introduction for the Arabic Reader (in Arabic). Dar Al-Nahda Al-Arabiya.

[6] Al-Sharwani, Ahmed bin Mohammed. (1906). Nafhat al-Yaman fi-ma yazulu bi-dhikrihi al-shajan (The whiff of Yemen from what by its mention, the sadness disappears) (in Arabic). Scientific Progress Press, Egypt, p. 179.

[7] Al-Tha'alibi, 'Abd al-Malik ibn Muhammad. (died: 429 AH). Representation and Lecture (in Arabic). Investigated by: AbdelFattah Mohammed Al-Helou, Al-Dar Al-Arabia lil-Kotob, $2^{\text {nd }}$ Edition, 1981, p. 154.

[8] Al-Tabari, Abu Ja'far Mohammed ibn Jarir. (died: 310 AH). History of the Prophets and Kings (in Arabic). Investigated by: Mohammed Abu Al-Fadl Ibrahim, (1967), House of Revival of Arab Heritage, Beirut.

[9] Al-Zabidi, Muhibb-ud-Deen Abu Faid Al-Sayyid Muhammad Murtada Al-Husseini Al-Wasiti. (1965). Taj al-Arus Min Jawahir al-Qamus [The Bride's Crown from the Pearls of the Qamus (Dictionary] (in Arabic). Investigated by: A group of investigators, Dar Al-Hedaya, Kuwait.

[10] Austin. (1991). The Theory of Speech Acts: How We Get Things Done with Words. Translated into Arabic by: Abdelkader Kenini, East Africa for Publishing.

[11] Bourdieu, Pierre (1994). Symbolic violence: A research in the origins of educational sociology (in Arabic). Translated into Arabic by: Nazeer Jahil, The Arab Cultural Center, Beirut.

[12] Deutscher, Guy. (2015). Through the language glass: Why the world looks different in other languages (in Arabic). Translated into Arabic by Hanan Abdul Mohsen Muzaffar, Kuwait, The World of Knowledge Magazine, The National Council for Culture and Arts.

[13] Greenfield, Susan. (2017). Mind change: How digital technologies are leaving their mark on our brains (in Arabic). Translated into Arabic by: Thab Abdel Rahim, Kuwait, The World of Knowledge Magazine, National Council for Culture and Arts.

[14] Juman, Mohammed Salam. (2010). Does violence feed on literature? Aqlam Jadidah Journal, University of Jordan, Issue 33, 105-110.

[15] Lakoff, George. (2005). The Gulf War or metaphors that kill (in Arabic). Translated into Arabic by: Abdulmajid Jahfa \& Abdulilah Salim, Dar Toubkal, Casablanca.

[16] Lecercle. (2005). Language violence (in Arabic). Translated into Arabic by: Mohammed Badawi, The Arab Organization for Translation, Arab Scientific Publishers, Beirut, p. 21.

[17] Lykoff, George; \& Johnson, Mark. (2009). The Metaphors We Live by (in Arabic). Translated into Arabic by Abdulmajid Jahfa, $2^{\text {nd }}$ Edition, Casablanca, Dar Toubkal.

[18] Meshri, Morsi. (2012). Digital social networks: a look at functions (in Arabic). Journal of the Arab Future, Center for Arab Unity Studies, 34, (3), 149 -169.

[19] Quraan, \{Surat Al-Zukhruf (43), verse (74)\}.

[20] Ogden, Richard. (n.d). The Meaning of Meaning: A Study of the Impact of Language on Thought and the Science of Symbolism (in Arabic). Translated into Arabic by: Kayan Ahmed Hazem Yahya, New Book House.

[21] Saqir, Nabil Mohammed. (2015). The pragmatic thought of John Searle: A reading in the interpretation mechanisms of indirect speech acts (in Arabic). Muqarabat Journal, Muqarabat Foundation for Publishing, Cultural Industries and Communication Strategies, 22, 87-99.

[22] Sforza, Luigi. (2004). Genes, peoples and languages (in Arabic). Translated into Arabic by: Ahmed Mostajir, The National Translation Project.

[23] Searle, John. (2006). Mind, Language And Society: Philosophy In The Real World (in Arabic). Translated into Arabic by: Saeed Al-Ghanimi, Publications of Difference \& the Arab Cultural Center, Publishers, Casablanca, Morocco.

[24] Tuaima, Rushdi Ahmed; \& Al-Naqa, Mahmoud Kamel Hassan. (2015). The concept and functions of language (in Arabic). International Scientific Conference: The Arabic Language and the Phenomena of Linguistic Variation and Linguistic Security, 
Lahaye University in the Netherlands and Zarqa University, Research and Language Development Center, Jordan, Lahaye University in the Netherlands and Research and Development Center / Al-Sanasil Journal, Amman Jordan, 15, 145-197.

[25] Waheeb, Majid Ayal. (2020). Violence in the grammatical thought among the Arabs: a study in the light of sociolinguistics (in Arabic). International Journal of Humanities and Social Sciences, College of Humanities and Social Sciences, Issue 15, 1-24.

[26] Wanasy, Siham. (2017). Violence: forms, factors and theories that explain it (in Arabic). Afak for Science Journal, Ziane Achour University of Djelfa, Issue 9, pp 248-265.

[27] Veague, H. B. (2015). The Psychology of Self-Harm: Cutting and self-harm (in Arabic). Translated into Arabic by: Ahmed, Khaled Khader; Othman, Manal Mustafa; \& Khattib, Mohammed Ahmed. (2015). $1^{\text {st }}$ edition. Arab Knowledge Bureau. p. 4.

Jinan Al-Tamimi, is an associate professor of Arabic Language at Prince Sattam Bin Abdulazziz University, Saudi Arabia. Received her Ph.D. degree in Arabic language (2012) from King Saud University. Her research interests include linguistics, cognitive linguistics, language, thinking, and digital communication. 